\title{
Risk advantages of platform technologies for biorenewable chemical production
}

2 Sampath Gunukula ${ }^{\mathrm{a}}$, Peter Keeling ${ }^{\mathrm{b}}$, Robert Anex ${ }^{\mathrm{a} *}$

$3{ }^{a}$ Biological Systems Engineering Department, University of Wisconsin, Madison, WI, 53706, USA

$4{ }^{\mathrm{b}}$ The Center for Biorenewable Chemicals, Iowa State University, Ames, IA, 50011, USA

5 Abstract

Recent investments in bio-based chemical development are financing the construction of commercial production facilities, often designed to produce a single biorenewable chemical.

8 Investments in technologies targeting a single biorenewable chemical are subject to significant 9 technological and market risks. Platform technologies that can convert biomass into a range of 10 related biorenewable chemicals can reduce these risks significantly. Researchers are now 11 developing platform technologies that combine bio-and chemical-catalysis, such as a process of 12 converting glucose into fatty alcohols of specific carbon chain length. The financial risk and 13 profitability of investments in platform technology producing fatty alcohol of different chain 14 length were analyzed. A techno-economic model to evaluate single- and platform technologies 15 was developed. A platform technology that can produce two products: 1-decanol and a blend of dodecanol and 1-tetradecanol reduces financial risk of investment by $23 \%$ and increases

17 profitability by 55\% compared to production via single-product technologies. This financial 18 advantage of two-product technology is eliminated as the cost of switching between products rises above \$4 MM for a 14 metric-ton/yr plant. Investments in technologies that can produce a 20 larger number of products provide higher returns lower risk. Other less quantifiable risk 21 advantages of platform technologies that nonetheless important are also discussed.

22 Key words: Platform technology, biorefinery, biorenewable chemical, financial risk,

23 biocatalysis, chemical catalysis

*Corresponding author. Tel.: +1 (608) 890-3839

E-mail address: anex@wisc.edu (Robert Anex)

(C) 2015. This manuscript version is made available under the Elsevier user license http://www.elsevier.com/open-access/userlicense/1.0/ 


\section{Introduction}

Most industrial chemicals used as materials, plastics, surfactants and solvents are currently derived from petroleum feedstock. Depleting non-renewable petroleum feedstock and environmental considerations have been drastically changing the prospects for renewable biomass as a raw material for industrial chemicals (Brehmer et al., 2009). In order to transform the petroleum-based chemical industry to a bio-based chemical industry, a substantial amount of research is ongoing throughout the world targeting one biorenewable chemical at a time. For example, Burk et al., (2011) describe a biological process for converting sugars into 1, 4butanediol; bio-isoprene can be synthesized by genetically modifying microbial cells to overexpress levels of an isoprene synthase polypeptide and a mevalonate kinase polypeptide (Beck et. al, 2010); and biobased chemical company Rennovia, Inc. is commercializing a catalytic process for the production of adipic acid from carbohydrates (Boussie et al., 2014).

Unfortunately, this approach of developing single-product technologies is slow and costly, as it requires all the investment in time and money for one chemical. Moreover, investing capital for producing biorenewable chemicals via technologies that yield a single-product magnifies a variety of the technological and market risks that characterize the highly competitive chemicals industry. Volatility in prices of feedstock, energy, and the market demand for chemicals are just a few of the sources of market and financial risk of investment in the biorenewable chemical business (Curtis, 2010). Since biorenewable chemicals can either structurally or functionally replace existing petrochemicals, renewable chemicals compete for market share with existing petrochemical products. Thus, there is a risk of reduction in market price as supply is increased by new market entry and a risk of aggressive price reduction by incumbent petrochemical companies, whose capital investments are already partially or fully 
47 depreciated. During the scale-up of pioneer renewable chemical technologies, there is risk of 48 process failure due to technical barriers, characterized as technology risks (Edwards and Eng, 49 2015). Furthermore, lack of economies-of-scale may create a barrier to market entry for low 50 profit margin biorenewable chemicals synthesized via single-product technologies. The various risks to the investments in the biorenewable chemical business may be 52 reduced by producing biorenewable chemicals via platform technologies. We define a 53 technology as a platform technology when it meets following criteria: 1) it enables the synthesis 54 of multiple chemicals; 2) the technological investments made in the synthesis of each chemical 55 are at least partially used in the research and development of one or more other chemicals; 3) the 56 production of each chemical in the platform uses at least $60 \%$ of the same plant equipment as the 57 other products in the platform - in other words, it should enable the plant to make multiple 58 chemicals by slightly modifying existing production equipment; and, 4) the products made using 59 the chemicals platform can be sold in different market segments. The platform concept fits into 60 one class of biorefinery identified by Sadhukhan et al., (2014) in which a portfolio of products 61 are derived from a single biomass feedstock using flexible conversion processes. Thus, the 62 development of platform technologies can expedite the development of a biorefinery that 63 operates similarly to an oil refinery. The recent development of a reverse $\beta$-oxidation pathway in E.coli as reported by 65 Cintolesi et al., (2014), for example, facilitates the synthesis of a range of di-carboxylic acids 66 with varying carbon chain length from glucose. This technology is considered a platform 67 technology for the following reasons: Of these di-carboxylic acids, medium chain di-acids such 68 as adipic acid can address the needs of the nylon industry (Taylor et al., 2015), and the long 69 chain di-acids such as octadecanedioic acid have applications in polyamide, polyurethanes, 
70 lubricants and adhesive industries (Greenwood, 2013). Since the mechanism with which the

71 reverse $\beta$-oxidation pathway in E.coli that makes medium and long chain di-acids is similar, the

72 technological advancements made in the development of bio-catalytic technology to synthesize

73 medium chain di-acids are applicable to the synthesis of long chain di-acids. Although separation

74 and purification processes are somewhat different for medium and long-chain di-acids, the

75 production of these di-acids will utilize a substantial portion of the same equipment including the

76 seed and product fermentors.

77 Platform technologies for biorenewable chemical production can be developed using 78 purely biological, purely chemical, integration of biological and chemical processes, or 79 thermochemical processes. The above mentioned reverse $\beta$-oxidation pathway in E.coli to 80 synthesize various di-acids is considered as an example of a purely biological method. Similarly, 81 synthesis gas from the thermochemical conversion of biomass can be used to synthesize a range 82 of products, including paraffins and olefins using the Fisher-Tropsch process $(\mathrm{Ng}$ and 83 Sadhukhan, 2011) and methanol using $\mathrm{Cu} / \mathrm{Zn} / \mathrm{Al}$ catalyst (Hamelinck and Faaij, 2002).

One example of a purely chemical approach is the oxidation of glucose over a platinum 85 catalyst which yields glucaric acid (Boussie et al., 2010). This glucaric acid subsequently 86 undergoes selective dehydration to lactones or selective esterification to polyglucaric esters 87 (Werpy et al., 2004). Another example is the catalytic dehydration of fructose to 588 hydroxymethylfurfural (Pagán-Torres et al., 2012), which can be further transformed 89 catalytically into various bio-fuels and bulk chemicals (Boisen et al., 2009). As an example of 90 an integrated approach, triacetic acid lactone is produced biologically from sugars through 91 overexpression of 2-pyrone synthase in Saccharomyces cerevisiae (Cardenas and Da Silva, 2014) 
92 and this biological intermediate is catalytically upgraded to sorbic acid, hexenoic acid, and $\gamma$ 93 caprolactone (Chia et al., 2012).

The concept of a platform technology is somewhat related to, but different from platform chemicals, as described by Werpy et al. (2004), who identified the most promising building 96 block chemicals that can be derived from biomass. Among the building block chemicals 97 identified by Werpy et al. (2004), most of chemicals can be produced via microbial technology, 98 and subsequently upgraded to yield a diverse portfolio of biorenewable chemicals using a 99 chemical catalyst (Shanks, 2007). 101 developing three platform technologies by integrating bio- and chemical- catalysis (The Center 102 for Bio renewable Chemicals, 2008). One of these three technologies is the carboxylic acid 103 platform technology (Liu and Jarboe, 2012). In this platform, microbial strains such as E.coli are 104 engineered to synthesize various carbon chain lengths of fatty acids from glucose via the fatty 105 acid biosynthesis pathway (Zhang et al., 2011), and these fatty acids are subsequently upgraded 106 to yield fatty alcohols of different carbon chain length using a chemical catalyst (Gervajio, 2012) 107 (Fig.1). The medium- and long-chain fatty alcohols are used in perfume, fragrances, cosmetics, 108 pharmaceutical, and surfactant and lubricant industries (Noweck and Grafahrend, 2006).

In this paper we analyze and compare the risks of investment in technologies for 110 producing fatty alcohols of different chain length via both single-product and platform 111 technologies. We quantitatively analyze financial risk and the profitability of investment, and 112 qualitatively evaluate other risks of investments in developing single and platform technologies. 113 Financial risk is quantified by assuming all the risk due to variation in prices is captured in the 
114 standard deviation of the probability density function of net present value (NPV) of irreversible

115 capital investment $^{1}$ in biorenewable chemical production (Amigun et al., 2011; Damodaran,

116 2008). The expected values of the probability density function of NPV are used as an indicator to

117 measure the profitability of an irreversible investment: as the expected NPV increases, provided

118 it is positive, the profitability of an irreversible investment will increase (Amigun et al., 2011).

119 Technology risk is quantified by estimating the likelihood of process failures that occur during 120 scaling-up a novel bio-renewable chemical technology. Such an estimation of process failures

121 requires a very large amount of process performance data from commercialized renewable

122 chemical technologies (Edwards and Eng, 2015). Unfortunately, at this point in time these data

123 for biorenewable chemical technologies are limited, because the biorenewable chemical industry

124 is still in its infancy. It is also very difficult to predict risks of scientific breakthroughs and 125 competitive market behavior. Thus, we qualitatively analyze these other risks and advantages of 126 platform technologies that are currently impossible to quantify. and platform technologies for producing fatty alcohols of different chain length using process

129 simulation software. We create a techno-economic model by estimating capital and operating 130 costs using simulated material and energy balances. The prices of feedstock, energy and products 131 are modeled as a mean-reverting process. A switching rule based on cost of switching between 132 products is developed and used in the economic model to represent profit-seeking plant 133 operation. A Monte Carlo simulation is performed to predict the probability distribution of NPV 134 of investment in fatty alcohol production. Comparison of the expected value and standard 135 deviation of distributions NPV for technologies that can reach one or more products has shown

\footnotetext{
${ }^{1}$ The capital invested in a chemical plant cannot be fully recovered when the plant is retired or retrofitted, thus investment in a chemical plant is characterized as an irreversible investment (Dixit and Pindyck, 1994)
} 
136 that the carboxylic acid platform technology can reduce the financial risk and increase the

137 profitability of investment. The influences of product carbon chain length and switching cost on

138 the risks of investment in platform technologies are investigated. Finally, we qualitatively

139 evaluate other risk impacts of platform technologies.

140 2. Methodology

$141 \quad 2.1$ Description of fatty alcohol production process

The process flow diagram for fatty alcohol production from glucose is shown in Fig. 2.

143 The annual plant capacity and plant life are taken to be 40,000 metric tonnes of glucose 144 conversion and 20 years, respectively. The process flow diagram is similar for both the single145 product and platform technologies for fatty alcohol production. However, in the platform 146 technology the versatility of the fatty acid biosynthesis pathway makes it possible to produce 147 fatty acids with varying carbon chain lengths. The versatility of this pathway is achieved by 148 introducing a unique acyl-ACP thioesterase gene into a microorganism for the synthesis of a 149 specific chain length of fatty acid. For instance, expressing class I acyl-ACP thioesterase genes 150 into a microorganism can terminate fatty acid chain elongation and produce the myristic acid 151 (C14:0), whereas expressing class III acyl-ACP thioesterase genes into a microorganism enables 152 the synthesis of octanoic acid (C8:0) (Jing et al, 2011). In this production process, the 153 biologically produced fatty acid then undergoes hydrogenolysis over a copper chromite catalyst 154 to yield a fatty alcohol (Gervajio, 2012).

The fatty alcohol production process starts with adding preserved genetically modified

156 E.coli seed culture to the first bioreactor in the seed fermentation train which consists of series of 157 bioreactors that increase incrementally in size by a factor of 10 (Humbird et al., 2011). Once the 158 E.coli cells are grown to a fixed concentration, the entire cell culture is transferred into the 
159 subsequent bioreactor in the seed train. This process is repeated until the cell count and 160 concentration required for the fatty acid production process is achieved in the final bioreactor of seed train. Glucose and other nutrients are added at each stage as necessary for E.coli growth.

The E. coli cells from the final bioreactor in the seed train are sent to the aerobic 163 production fermentor, operating at $37^{0} \mathrm{C}$ in fed-batch mode, to synthesize fatty acid from glucose 164 under M9 minimal media. During product fermentation, $\mathrm{CO}_{2}$ is evolved as a gas and fatty acid is 165 produced as an extracellular product. The separation of E.coli cells from the fermentation broth 166 containing fatty acid, E.coli cells and other impurities is achieved using a rotary vacuum filter.

167 Fatty acid from the clarified fermentation broth is extracted using solvent extraction column 168 with the aid of the extracting agent chloroform (López-Garzón and Straathof, 2014). The 169 extractant phase of the solvent extraction process containing chloroform and fatty acid is 170 separated into pure fatty acid and chloroform using distillation. Vacuum distillation and 171 decantation processes are used to recover solvent present in the raffinate phase of solvent 172 extraction process.

174 over a bimetallic catalyst in a catalytic reactor. After high pressure hydrogenation process, the 175 mixture of hydrogen, fatty alcohol, and catalyst slurry from the catalytic reactor is sent to the 176 two-stage cooling/expansion system to recover unreacted hydrogen that is later mixed with the 177 make-up hydrogen before recycled to the hydrogenation reactor. Using a basket centrifugal 178 separator, the fatty alcohol/catalyst slurry stream is separated into a fatty alcohol stream with 179 some traces of solids and a catalyst slurry stream. The catalyst slurry is recycled to the catalytic 180 reactor, and the solid traces in the fatty alcohol stream are removed by the filter (Gervajio, 2012).

\subsection{Process simulation}


183 fermentation, vacuum filtration, and countercurrent solvent extraction using rotating disc 184 contactor column, because this software provides necessary models of these processes that are 185 not available in Aspen Plus ${ }^{\circledR}$ Version 8.6, (2014). The biomass growth in the seed train was 186 modeled by Monod kinetics with a maximum specific growth rate of $0.4 \mathrm{hr}^{-1}$ and a biomass yield 187 of $0.4 \mathrm{~g}(\mathrm{dcw}) / \mathrm{g}$ glucose. For the modeling of production fermentor it was assumed that there is 188 no biomass growth, and the product yield is $0.34 \mathrm{~g}$ fatty acid/g glucose. The information on 189 operating conditions and other modeling parameters that are required for the simulation of the 190 seed and product fermentors were obtained from personal communication with the CBiRC 191 development team (Table S1). SuperPro Designer ${ }^{\circledR}$ process simulation software was used to 192 simulate the seed and product fermentors for the fatty acid production. The necessary area of the rotary vacuum filter to remove E.coli cells from the 194 fermentation broth and number of stages, diameter and height of the solvent extraction column 195 were estimated using the SuperPro Designer ${ }^{\circledR}$ process simulation software. The needed design 196 parameters for the solvent extraction column simulation were determined as described in our 197 unpublished work (Table S2). Aspen Plus ${ }^{\circledR}$ was used for simulation of the overall process, excluding fermentation, 199 filtration, and solvent extraction processes, because it is the accepted industry standard process 200 simulation software that provides sophisticated models of vapor-liquid equilibrium separations 201 and chemical reactions which allowed us to more accurately simulate distillation and catalytic 202 reactions. The simulated extractant and raffinate material flows of solvent extraction process 203 were imported into Aspen Plus ${ }^{\circledR}$ software, which were used as inlet streams to distillation 204 columns. The RadFrac method was used to perform the simulation of distillation columns. 
205 Distillation column simulation defined the required number of trays and column diameter for the

206 particular separation. The Aspen Plus ${ }^{\circledR}$ shell and tube model was utilized to determine the areas

207 of the condenser, reboiler, and heat exchanger columns in the fatty alcohol process.

For the design of catalytic reactor, we selected an operating temperature of $553 \mathrm{~K}$ and 30 MPa which yield nearly $100 \%$ conversion of fatty acid with $95 \%$ selectivity to fatty alcohol (Gervajio, 2012). We could not obtain kinetic data related to the high pressure hydrogenolysis of

211 saturated fatty acid so the catalytic reactor was modeled using the Aspen Plus ${ }^{\circledR}$ stoichiometric

212 reactor model. The two-stage cooling/expansion, and centrifugal separator processes were also 213 modeled using the Aspen Plus ${ }^{\circledR}$ process simulation software. Required design parameters and 214 operating conditions for these processes were determined using standard engineering methods 215 (Seider et al., 2010). In this work we did not model any wastewater treatment processes and 216 utility production. Instead, utilities were assumed to be purchased from an external facility and 217 wastewater was assumed to be treated by an external facility for a fixed price.

\subsection{Economic model and key assumptions}

An Excel VBA (Visual Basic for Applications) economic model was developed using 220 discounted cash flow analysis (DCF) to determine the distribution for the NPV of an investment 221 for both single-product and platform technologies. The simulated material and energy balances 222 data were imported into Excel spreadsheet from SuperPro Designer ${ }^{\circledR}$ and Aspen Plus ${ }^{\circledR}$ models. 223 The amount of raw materials, natural gas, cooling water, and electricity required for the fatty 224 alcohol production were determined using material and energy balance data. The operating 225 labor-related charges were estimated using a correlation between operating labor and plant 226 capacity as described by Peters and Timmerhaus (1991). The maintenance wages and benefits 227 (MW\&B) were assumed to be $4.5 \%$ of total direct plant cost. The maintenance overhead and 
228 other maintenance related costs were calculated as 135\% of MW\&B (Seider et al., 2010). The

229 operating overhead and property taxes were assumed to be $23 \%$ and $2 \%$ of labor cost and total 230 direct plant cost, respectively (Seider et al., 2010). Annual plant depreciation was computed 231 using the Modified Accelerated Cost Recovery Systems (MARCS) method (Peters and 232 Timmerhaus, 1991). Total general expenses were estimated as $10 \%$ of total revenues generated 233 from fatty alcohols (Seider et al., 2010).

Equipment costs of seed and product fermenters, vacuum filter, and solvent extraction 235 column were calculated using a built-in cost model in the SuperPro Designer ${ }^{\circledR}$ simulation 236 software. Distillation column purchase cost was estimated based on the number of trays and 237 diameter (Peters and Timmerhaus, 1991). The cost of the catalytic reactor was computed using a 238 design equation from Peters and Timmerhaus (1991) based on the reactor type and volume. The 239 condenser, reboiler, and other heat transfer equipment purchase costs were estimated using a cost 240 correlation method based on heat transfer area (Seider et al., 2010). An empirical equation based 241 on bowl diameter presented in the Seider et al., (2010) was utilized to calculate the purchase cost 242 of basket centrifuge. The equipment costs were indexed to US \$2014 prices using chemical 243 engineering plant cost indices (Chemical Engineering Plant Cost Index (CEPCI), 2015). ratio factors based on the equipment purchase cost quoted in Peters and Timmerhaus (1991, pp. 246 182). The prices for glucose, nutrients, solvents, utilities, catalyst and product were obtained 247 from market data. Future cash flows were projected over the plant life using incurred operating 248 costs and sales of a fatty alcohol. After deducting taxes, at the rate of $39 \%$ on the gross profit 249 provided it is positive, from gross profit gave us net profit for each operating day. These net 250 profits were discounted to the year 2014 at the fixed internal rate of return of $10 \%$. NPV of an 
251 investment was calculated by subtracting the total investment cost from the summation of all 252 discounted net profits over the plant life.

253 Variables in the economic model that cause uncertainty in fatty alcohol sales, operating 254 costs, and ultimately NPV of an investment are the price of feedstock (i.e., glucose), price of 255 product (i.e., fatty alcohol), price of hydrogen, price of catalyst (i.e., copper-chromite), price of 256 electricity, and the price of natural gas. We assume that although input prices move up and down 257 in the short run, they revert to the marginal cost of production in the long run (Dixit and Pindyck, 258 1994). Therefore, in the DCF analysis, price dynamics were modelled as stochastic mean259 reverting processes (Dixit and Pindyck, 1994). The following mean-reverting process equation 260 was used to model economic variables:

$$
x_{t}=x_{t-1}+\eta(\bar{x}-x) \mathrm{dt}+\sigma \epsilon_{\mathrm{t}} \sqrt{\mathrm{dt}}
$$

Here, $\eta$ is the speed of reversion; $x_{t}$ is the commodity price at time $\mathrm{t} ; \bar{x}$ is the long-run 263 marginal price of the commodity or long term mean; $\sigma$ the variance parameter; $x_{t}-x_{t-1}$ is the 264 change in price over any time interval $\mathrm{dt}$; and $\epsilon_{\mathrm{t}}$ is a random number with zero mean and unit 265 standard deviation. Mean-reverting process parameters for the respective economic variables 266 were estimated from historical time series data. We obtained historical glucose price data from 267 the United States Department of Agriculture, (2014); fatty alcohol price data from ICIS chemical 268 pricing, (2014); hydrogen, natural gas, and electricity price data from the United States Energy 269 Information Administration, (2014); copper and chromium data from United States Geological 270 Survey, (2014). Sample paths were generated for each economic variable over the plant life by 271 calculating a trajectory for $x_{t}$ with a time interval $(\mathrm{dt})$ of one day using Mean-Reverting process 272 equation. 
The Monte Carlo simulation then randomly drew values from each trajectory of

274 economic variable to generate a unique set of market prices and costs from which NPV was

275 computed. The entire distribution of all draws $(10,000)$ resulted in a NPV distribution for

276 investment in a single-product technology as well as the platform technology.

\section{$277 \quad 2.4$ Switching cost}

In principle, with a platform technology a chemical company could switch products many

279 times, but in practice this is unlikely. Whenever a chemical company switches its production

280 from one product to another, it incurs the cost of process conversion $\left(X_{s w}\right)$. We break this cost

281 into one-time and recurring switching costs. When a change in technology, taken as an example

282 for one-time switching cost, requires different separation equipment, chemical companies will

283 have to invest only on one occasion to purchase this equipment. Once the firm has switched, they

284 own the equipment. While in other cases, for example replacing an expensive noble metal 285 catalyst with another in order to switch the production, an investment is necessary for each 286 switching because chemical firms generally lease an expensive metal catalyst. Thus there is a 287 cost associated with each switch between products that is characterized as recurring switching 288 cost.

Since switching the production from one chemical to another requires additional 290 investment (switching cost), a chemical firm will switch production only when the economic 291 return generated from switching production is greater than the switching cost. Following this 292 logic, a switching rule based on switching cost was developed to determine the possibility of 293 switching among different products with platform technologies at any future time. The 294 development of switching rule is explained in detail in the supplementary material of this paper. 
We used this switching rule in the aforementioned Excel VBA model to determine the

probability distribution of NPV of an investment for the carboxylic acid platform technology. At each time period $\mathrm{t}(\mathrm{t}=0,0.25 \mathrm{yr}, 0.5 \mathrm{yr}, \ldots 20 \mathrm{yrs}$.$) , the developed Excel VBA model compares$ the net profit from the current product production with the net profit from the alternative product production, and if the net profit from current product production is less than that of the alternative product production, then the decision to switch to an alternative product will be made based on the switching rule. When the decision to be made is switch to an alternative product at any future time $t$, the switching cost is discounted to the current time, $t=0$, at a rate of return (r)

303 of $10 \%$ and added to the total capital investment.

\section{Results and discussion}

\subsection{Quantitative analysis of platform technology}

In this section, we quantify and compare the financial risk and profitability of an irreversible investment for the production of fatty alcohol via single-product and carboxylic acid platform technologies. We assume single product technologies produce blend of 1-dodecanol and 1-tetradecanol or 1-decanol from glucose, and the 2- product carboxylic acid platform technology can convert glucose into a blend of 1-dodecanol and 1-tetradecanol and has a flexibility to switch to 1 -decanol with the switching cost of $\approx 0$. The switching cost is assumed to be zero because the production of one fatty alcohol to another fatty alcohol using the carboxylic 313 acid platform technology is simply achieved by changing the bio-catalyst.

Both single and 2- product platform technologies are modeled using process simulation software to estimate steady state flow rates of products and raw materials. The capital expenses 
318 fatty alcohol, natural gas, electricity, copper chromite catalyst, hydrogen prices) are generated over the plant life of 20 years following mean revering processes. Parameters required for the mean reverting process are determined through linear regression using historic time series data

321 (Table 2). With this information, an Excel VBA based-model was developed to determine NPV

322 of an investment. Monte Carlo simulation is then performed to derive a distribution for the NPV 323 of an investment for a fatty alcohol production via single and 2- product platform technologies.

The resulting probability density functions of NPV are graphed in Fig. 3. Deriving the 325 NPV distribution of an investment in a project that employs a single-product technology to convert glucose into blend of 1-dodecanol and 1-tetradecanol, an expected value of \$12 million and standard deviation of $\$ 25$ million are estimated. The average value and the standard deviation of NPV distribution are found to be \$20 million and \$26 million respectively for the 329 investment in single-product technology that can produce 1-decanol from glucose (Fig. 3). If the 330 investment is made in the 2- product platform technology that has a flexibility to switch to an 331 alternative fatty alcohol, the project mean and standard deviation of NPV distribution are 332 calculated as \$ 31 million and \$20 million, respectively (Fig. 3). The difference between two mean NPVs, that is, \$ 31 million - \$ 12 million and \$ 31 million - \$20 million determine the increase in profitability of an investment by 2- product platform technology compared to singleproduct technologies. Comparing standard deviation of NPV distribution of investment for 2336 product platform technology, that is, \$ 20 million with that of single-product technology, that is, 337 \$ 25 million and \$ 26 million shows that financial risk due to volatilities in prices of product, 338 feedstock, energy, and catalyst is reduced by the 2-product platform technology.

This reduction in financial risk and increase in profitability of investment with the 2340 product platform technology will be explained as follows. For example, Fig. 4 shows the five- 
341 year forecasted net profits that are generated from the blend of 1-dodecanol and 1-tetradecanol

342 and 1-decanol production via single-product technologies. If a technology only makes one

343 product (either blend of 1-dodecanol and 1-tetradecanol or 1-decanol), a chemical firm must live

344 with the up and down swings of these net profits that are caused due to volatilities in market

345 prices of product, feedstock, energy, and catalyst. However, suppose the chemical firm has the

346 platform technology to produce multiple products. If the net-profits of an alternative product

347 become more attractive, the chemical firm can consider switching. The expectation to switching

348 is that market prices of product, feedstock, energy, and catalyst will revert toward their long-term

349 means, that the net-profit difference may not justify the cost of switching production. This ability

350 to switch between products with platform technologies reduces the impact of market volatility

351 and increases value of the investment.

\section{$352 \quad 3.2$ Impact of multiple products}

353 In this section, we analyze how the increase in the number of products in the "product

354 suit" of platform technology impacts the financial risk and profitability of investment. The

355 product suit of single-product technologies contain only one product, and the product suites of 356 two, three, and four product platform technologies contain two, three, and four products 357 respectively.

The financial risk and profitability of investment for making 1-octanol, 1-decanol, blend of 1-dodecanol and 1-tetradecanol, and 1-hexadecanol via single-product technologies are

360 determined by deriving probability density function of net present value (Table 3). The prices of 361 1-octanol and 1-hexadecanol are modeled using mean reversion process, and required mean 362 reversion parameters are estimated from their respective historical data (Table 2). The estimated 363 operating costs of 1-octanol production are slightly higher than the 1-decanol production, and of 
1-hexadecanol production are slightly lower than the 1-decanol production. The results

365 summarized in Table 3 show that as the profitability of investment for the fatty alcohol

366 production via single-product technologies increases the financial risk to investment also

367 increases. Among the four fatty alcohols analyzed in this work, the investment for the production

368 of 1-octanol has high profitability and financial risk, and for the production of 1-hexadecanol has

369 low profitability and low financial risk (Table 3). This high profitability is due to the high long

370 term mean price of 1-octanol compared to other fatty alcohols, and the high financial risk is a

371 result of high volatility or variability in the price of 1-octanol (Table 2).

In order to compare the economic value of investment for synthesis of fatty alcohols 373 using 2-product platform technologies with that of single-product technologies, NPV of

374 investment for all possible product suites of 2-product platform technologies with four fatty

375 alcohols are estimated (Table 3). It is found from results that the profitability of investment 376 increases and financial risk of investment decreases with 2-product platform technologies 377 compared to single-product technologies (Table 3). However, the economic value generated 378 from 2-product platform technologies with a product suit of 1-hexadecanol and 1-octanol, 1379 decanol, or blend of 1-dodecanol and 1-tetradecanol is similar to that of single-product 380 technologies making 1-octanol, 1-decanol, and blend of 1-dodecanol and 1-tetradecanol, 381 respectively. This exception is because net revenues generated from 1-hexadecanol production 382 over the simulated time period is always less than that of other fatty alcohols, and thus it is not 383 attractive to consider switching to 1-hexadecanol production with a 2-product platform 384 technology. Thus, the addition of low value product such as 1-hexadecanol to the product suit of 385 platform technology will not improve the economic value of investment for the synthesis of 386 biorenewable chemicals using platform technologies. 
Since the product suit of 2-product platform technology having 1-hexadecanol will not add any value to the investment, we analyze product suit of 3-product platform comprising only 1-octanol, 1-decanol, and blend of 1-dodecanol and 1-tetradecanol. The probability distribution of NPV of an opportunity of investment for the fatty alcohol production via 3-product platform technology is calculated to determine financial risk and profitability of investment (Table 3). The results in Table3 show that the 3-product platform technology increases profitability of investment to $\$ 45$ million, which is higher than that of single- and 2-product technologies, and decreases the financial risk to $\$ 16$ million, which is lower than that of single- and 2-product technologies (Table 3). Thus, profitability of investment increases and financial risk of investment for the biorenewable chemical production via platform technologies decreases as the number of products in the product suit of platform technology increases. However, the extent of this impact on the economic value with the increase in number of products in the product suit of platform technology will depend upon the type of product in the product suit. For instance, as shown above the addition of low value product such as 1-hexadecanol to the product suit of platform technology can't improve the economic value of investment.

\subsection{Sensitivity to switching cost}

The production of fatty alcohols is a somewhat unique case. In general, there is a cost associated with platform technologies for switching from one product to another. In order to see how switching cost influences the economic advantages provided by platform technologies, profitability of investment for the synthesis of fatty alcohols via 2-product platform technology is computed for increasing one- time and recurring switching costs.

The profitability of investment for the 2-product platform technology allowing access to two markets 1-decanol and blend of 1-dodecanol and 1-tetradecanol for increasing recurring 
410 switching costs is estimated by exercising the economic model nested with Monte Carlo

411 simulation (Fig. 5). As shown in Fig.5, the profitability of investment decreases with increasing

412 recurring switching cost. Similar behavior in profitability is observed with increasing one-time

413 switching cost (data is not shown). This decrease in profitability is primarily because the 2-

414 product platform technology will allow its production to switch less and less as the switching

415 cost increases.

For the recurring switching cost of \$4MM (Fig.5) and one-time switching cost of \$6MM,

417 the profitability of investment for making fatty alcohols via 2-product platform technology

418 converges to the value provided by single-product technology. Hence, the economic advantage

419 provided by the 2-product platform technology allowing access to two markets (1-decanol and

420 blend of 1-dodecanol and 1-tetradecanol) vanishes when the switching cost is greater than

421 \$4MM in the case of frequent investment and greater than \$6MM in the case of one-time

422 investment.

One reason for the different maximum values for one-time and recurring switching costs

424 is the dependence of profitability of investment on discount rates. While exercising the economic

425 model nested with Monte Carlo simulation, switching cost is added to the total capital

426 investment in the case of one-time investment and in the case of frequent investment, switching

427 cost at the time of switching is discounted to the year of 2014 at the fixed internal rate of return

428 of $10 \%$, and then added to the capital investment. The application of discount rates that are less

429 than or greater than $10 \%$ will result in maximum values of recurring switching costs that are less

430 than or greater than $\$ 4 \mathrm{MM}$. In conclusion, the switching cost limits the commercial advantage

431 provided by the platform technologies irrespective of the nature of switching cost. In the 
432 following section, we will qualitatively state other advantages of platform technologies for 433 biorenewable chemical production.

\subsection{Qualitative risk analysis of the platform technology}

We have so far considered market risk due to variation in the prices seen in the market. Another dimension of market risk results from depression of the market equilibrium or long-term mean price of a chemical as new producers enter into the market. This reduction in equilibrium market price is dependent on the price elasticity of supply and demand of a chemical. Such price depression will decrease the current equilibrium price of a chemical and set a new equilibrium price (Mankiw, 2012). If the equilibrium price is highly sensitive to market supply and demand, there is more risk to the investment, particularly to the 'single-product' technology. For instance, the market price of ethane in the US fell nearly by 50 percent since 2005 as its production has increased from 700,000 barrels per day in 2005 to 1,000,000 barrels per day in 2013, as a result of the shale gas revolution (Chamberlin, 2014). If a technology only made ethane, there would be a high risk of incurring financial losses to a company if profit margins were low, as is often the case for commodity chemicals. An advantage of a platform technology is that if the market for one target product collapses, such as ethane in this example, the investment is not lost because production can shift to another chemical with a relatively small additional capital investment.

Another source of risk to the investment in the biorenewable chemical business is associated with scaling-up a new technology. When an incipient technology is scaled up from laboratory- to pilot-, to commercial scale, there is a risk of short fall in technology performance due to insurmountable technological barriers that are not identified at the research and development stage (Edwards and Eng, 2015). If a single-product technology experiences such insurmountable technical barriers, complete losses of capital and technical investments are 
455 likely. However, these losses are significantly reduced in the case of platform technologies. If 456 development of a particular technology, the synthesis of fatty alcohols from fatty acid for 457 example, fails to meet process performance targets during scale up, perhaps the chemical catalyst 458 cannot achieve necessary levels of selectivity under production conditions, much of the 459 technology of the carboxylic acid platform can simply be repurposed to target a different 460 molecule within the platform, such as n-alkanes (Mäki-Arvela et al., 2007). Thus, the 461 investments made in developing and commercializing the fermentation technology for fatty acid 462 production from biomass and the separation of fatty acids from fermentation media are saved and 463 redirected into another product line.

Platform technologies also provide an opportunity to deliver multiple commodity 465 chemicals to the market with one facility thus reducing production cost. Werpy et al. (2004) have 466 identified the most promising building block chemicals that can be derived from glucose. In 467 addition, they identified a diverse portfolio of chemicals that can be subsequently produced from 468 these building block chemicals. Most of the chemicals identified by Werpy et al. (2004) are 469 commodity chemicals with relatively small markets; much smaller than ethanol, for example. 470 This small market size limits the feasible capacity of a production facility if designed to produce 471 only a single-product. The high production cost due to the diseconomies of scale may create a 472 barrier for market entry for commodity chemicals, which generally have low profit margins. 473 Having the ability to produce multiple products using the same equipment, platform technology 474 makes it possible to capture the economies-of-scale possible from a large biorefinery- without 475 over supplying any individual product market. Investments in platform technologies for producing high-profit margin specialty 477 chemicals may over time lead to the production of commodity chemicals. In general, it requires 
478 large capital investment to construct high capacity plants for producing conventional commodity

479 chemicals. The requirement of such high capital investments will create a barrier entering into 480 the commodity chemical business. One strategy to overcome this barrier is to make a higher 481 value chemical via platform technology. If production and marketing of the first, higher-value 482 products is successful, technologies can be refined and de-risked. As technology risks decrease, 483 it may be possible for firms to take on more market risk. Firms will have both technological and 484 financial capacity to increase plant capacity as necessary to produce larger volume commodity 485 chemicals from biomass. For example, when investments made by a company in the microbial 486 production of specialty chemicals such as azelaic acid via reverse $\beta$ oxidation (Cintolesi et al., 487 2014) are profitable; then there is an opportunity to expand plant capacity in order to make a 488 commodity chemical such as adipic acid. chemicals with unique and improved properties. Such novel products can functionally replace 491 existing petro-chemicals or create new opportunities in the chemicals markets. The risk to the 492 capital investments for the synthesis of novel biorenewable chemicals via single-product 493 technologies is high as markets for these products are not yet developed and there is high 494 uncertainty associated with their market potential (Werpy et al., 2004). These risks can be 495 reduced by making novel products via platform technologies as technical and capital investments 496 of platform technologies can be spread over replacement, functional replacement, and novel 497 chemical products. Moreover, with platform technologies a company can adjust production 498 volumes of making drop-in and novel chemicals according to their market growth potentials.

\section{Conclusions}


There are several different types of risks associated with the production of biorenewable 501 chemicals. These risks reduce the profitability of capital investments in single-product 502 technologies and are a deterrent to investments in biomass conversion technologies. In this work, 503 we have shown quantitatively how platform technologies can reduce financial risks and increase 504 the value of investments in biorenewable chemical production relative to single-product 505 technologies. Platform technologies that produce a large range of different chemicals generate 506 higher returns with lower risk. The benefits of platform technologies are reduced as the cost of 507 switching between products increases. Platform technologies also reduce the risk of introducing 508 novel and low-market volume products to the market.

Biorenewable chemical companies may benefit from developing platform technologies, 510 particularly if they already have appropriate technical and marketing expertise. However, 511 bringing a product into a new market can be more expensive than developing the product and 512 often requires specialized technical skills as well. Thus capturing the benefit of making multiple 513 products from a single technology platform may significantly increase the total investment 514 required and reduce the appeal of platform technologies, particularly to smaller firms.

Firms that already operate facilities such as biofuel plants or biorefineries built around 516 corn wet or dry mills are likely to find it easiest to incorporate platform technologies to produce 517 a range of chemical and fuel products for the obvious reasons that these plants have some of the 518 requisite infrastructure and these firms have diverse technical talents. The exact type of 519 technology platform that makes the most sense for any firm, however, will depend on that firm's 520 endowment of technical and physical resources. Further research is required to define how 521 characteristics of a technology platform such as number of products, range of product markets, 
522 variability of market prices, correlation between market prices, and nature of separation

523 processes benefit the unique circumstance of a particular firm.

524 In general, the advantages of a multi-product approach improve the prospects for

525 developing biorefineries built around or incorporating platform technologies. Easing access to

526 capital through development of risk reducing platform technologies can stimulate the growth of

527 the biorenewable fuel and chemical industries. Targeting biobased chemical platform

528 technologies in research and development funding may therefore accelerate the growth of a

529 biobased economy.

\section{Acknowledgements}

531 The authors thank Thatcher Root (a professor from University of Wisconsin-Madison)

532 for his suggestions during this manuscript preparation. This work is financially supported by

533 National Science Foundation under grant No. EEC-0813570/1158833.

\section{References}

536 Amigun, B., Petrie, D., Görgens, J., 2011. Economic risk assessment of advanced process 537 technologies for bioethanol production in South Africa: Monte Carlo analysis. Renew. Energy. 53836 (11), 3178-3186. doi:10.1016/j.renene.2011.03.015.

539 Aspen Plus ${ }^{\circledR}$ Version 8.6, 2014. Aspen Technology Inc, Massachusetts.

540 Beck, Z.Q., Calabria, A.R., Miller, M.C., Vaviline, D.V., Wells, D.H., 2010. Increased isoprene 541 production using mevalonate kinase and isoprene synthase. Patent no. US20100184178 A1.

542 Boisen, A., Christensen, T.B., Fu, W., Gorbanev, Y.Y., Hansen, T.S., Jensen, J.S., Klitgaard, 543 S.K., Pedersen, S., Riisager, A., Ståhlberg, T., Woodley, J.M., 2009. Process integration for the 544 conversion of glucose to 2,5-furandicarboxylic acid. Chem. Eng. Res. Des. 87 (9), 1318-1327. 545 doi:10.1016/j.cherd.2009.06.010. 
Boussie, T.R., Dias, E.L., Fresco, Z.M., Murphy, V.J., Shoemaker, J., Archer, R., Jiang, H., 2014. Production of adipic acid and derivatives from carbohydrate-containing materials. Patent no. US8669397 B2.

Boussie, T.R., Dias, E.L., Fresco, Z.M., Murphy, V.J., 2010. Production of adipic acid and derivatives from carbohydrate-containing materials. Patent no. US20100317822 A1.

Brehmer, B., Boom, R.M., Sanders, J., 2009. Maximum fossil fuel feedstock replacement potential of petrochemicals via biorefineries. Chem. Eng. Res. Des. 87.9, 1103-1119. doi:10.1016/j.cherd.2009.07.010.

Burk, M.J., Van Dien, S.J., Burgard, A.P., Niu, W., 2011. Compositions and methods for the biosynthesis of 1,4-butandiol and its precursors. Patent no. US 8067214 B2.

Cardenas, J., Da Silva, N.A., 2014. Metabolic engineering of Saccharomyces cerevisiae for the production of triacetic acid lactone. Metab. Eng. 25, 194-203. doi:10.1016/j.ymben.2014.07.008.

Chia, M., Schwartz, T.J., Shanks, B.H., Dumesic, J.A., 2012. Triacetic acid lactone as a potential biorenewable platform chemical. Green Chem. 14 (7), 1850-1853. doi:10.1039/c2gc35343a.

Cintolesi, A., Clomburg, J.M., Gonzalez, R., 2014. In silico assessment of the metabolic capabilities of an engineered functional reversal of the $\beta$-oxidation cycle for the synthesis of longer-chain (C>4) products. Metab. Eng. 23, 100-115. doi:10.1016/j.ymben.2014.02.011.

Curtis, B., 2010. U.S. Biofuels industry: mind the gap. Concentric Energies \& Resource Group Inc, Report.

Damodaran, A., 2008. Strategic Risk Taking: A Framework for Risk Management. Pearson Education Inc, Upper Saddle River, New Jersey.

Dixit, A.K., Pindyck, R.S., 1994. Investment under Uncertainty. Princeton University Press, Princeton, New Jersey.

Edwards, D., Eng, P., 2015. Scaling up bioenergy technologies. Chem. Eng. Prog. 111 (3), 5861 .

Gervajio, G.C., 2012. Fatty Acids and Derivatives from Coconut Oil, Kirk-Othmer Encyclopedia of Chemical Technology. 1-38. doi: 10.1002/0471238961.fattgerv.a01.

Hamelinck, C.N., Faaij, A.P.C., 2002. Future prospects for production of methanol and hydrogen from biomass. J. Power Sources. 111 (1), 1-22. doi:10.1016/S0378-7753(02)00220-3.

Humbird, D., Davis, R., Tao, L., Kinchin, C., Hsu, D., Aden, A., Schoen, P., Lukas, J., Olthof, B., Worley, M., Sexton, D., Dudgeon, D., 2011. Process design and economics for biochemical conversion of lignocellulosic biomass to ethanol: Dilute-acid pretreatment and enzymatic 
578 hydrolysis of corn stover. National Renewable Energy Laboratory, Report No. NREL/TP-510057947764.

580 Jing, F., Cantu, D.C., Tvaruzkova, J., Chipman, J.P., Nikolau, B.J., Yandeau-Nelson, M.D., 581 Reilly, P.J., 2011. Phylogenetic and experimental characterization of an acyl-ACP thioesterase 582 family reveals significant diversity in enzymatic specificity and activity. BMC Biochem. 12 583 doi:10.1186/1471-2091-12-44.

584 Liu, P., Jarboe, L.R., 2012. Metabolic engineering of biocatalysts for carboxylic acids 585 production. Comput. Struct. Biotechnol. J. 3 (4), 1-9. doi:10.5936/csbj.201210011.

586 López-Garzón, C.S., Straathof, A.J.J., 2014. Recovery of carboxylic acids produced by 587 fermentation. Biotechnol. Adv. 32 (5), 873-904. doi:10.1016/j.biotechadv.2014.04.002.

588 Mäki-Arvela, P., Kubickova, I., Snåre, M., Eränen, K., Murzin, D.Y., 2007. Catalytic 589 deoxygenation of fatty acids and their derivatives. Energy and Fuels. 21 (1), 30-41. 590 doi:10.1021/ef060455v.

591 Mankiw, N.G., 2012. Principles of Economics, sixth ed. South-Western Cengage Learning, 592 Mason, Ohio.

593 Ng, K.S., Sadhukhan, J., 2011. Techno-economic performance analysis of bio-oil based Fischer594 Tropsch and CHP synthesis platform. Biomass and Bioenergy. 35 (7), 3218-3234.

595 doi:10.1016/j.biombioe.2011.04.037.

596 Noweck, K., Grafahrend, W., 2006. Fatty Alcohols, Ullmann's Encyclopedia of Industrial 597 Chemistry. doi: 10.1002/14356007.a10_277.pub2.

598 Pagán-Torres, Y.J., Wang, T., Gallo, J.M.R., Shanks, B.H., Dumesic, J.A., 2012. Production of 599 5-hydroxymethylfurfural from glucose using a combination of lewis and bronsted acid catalysts 600 in water in a biphasic reactor with an alkylphenol solvent. ACS Catal. 2 (6), 930-934. doi: $601 \quad 10.1021 / \operatorname{cs} 300192 z$.

602 Peters, M.S., Timmerhaus, K.D., 1991. Plant Design and Economics for Chemical Engineers, 603 fourth ed. McGraw-Hill Inc, New York.

604 Sadhukhan, J., Ng, K.S., Hernandez, E.M., 2014. Biorefineries and Chemical Processes: Design, 605 Integration and Sustainability Analysis. John Wiley \& Sons Ltd, Chichester, West Sussex.

606 Seider, W.D., Seader, J.D., Lewin, D.R., Widagdo, S., 2010. Product and Process Design 607 Principles: Synthesis, Analysis, and Evaluation, third ed. John Wiley \& Sons Inc, Hoboken, New 608 Jersey.

609 Shanks, B.H., 2007. Unleashing biocatalysis/chemical catalysis synergies for efficient biomass 610 conversion. ACS Chem. Biol. 2 (8), 533-535. doi: 10.1021/cb7001522. 
611 SuperPro Designer® Version 9.0, 2013. Intelligen Inc, Scotch Plains, New Jersey.

612 Taylor, R., Nattrass, L., Alberts, G., Robson, P., Chudziak, C., Bauen, A., Libelli, I.M., Lotti, G., 613 Prussi, M., Nistri, R., Chiaramonti, D., Contreras, A.L., Bos, H., Eggink, G., Springer, J., 614 Bakker, R., Ree, R.V., 2015. From the sugar platform to biofuels and biochemicals. Final report 615 for the European Commission, Contract No. ENER/C2/423-2012/S12.673791.

616 Werpy, T., Petersen, G., Aden, A., Bozell, J., Holladay, J., White, J., Manheim, A., Elliot, D., 617 Lasure, L., Jones, S., Gerber, M., Ibsen, K., Lumberg, L., Kelley, S., 2004. Top value added 618 chemicals from biomass - volume 1: results of screening for potential candidates from sugars 619 and synthesis gas. Pacific Northwest National Laboratory, National Renewable Energy

620 Laboratory and Department of Energy, Washington, DC. doi:10.2172/15008859.

621 Zhang, X., Li, M., Agrawal, A., San, K.Y., 2011. Efficient free fatty acid production in 622 Escherichia coli using plant acyl-ACP thioesterases. Metab. Eng. 13 (6), 713-722.

623 doi:10.1016/j.ymben.2011.09.007.

624 The Center for Bio renewable Chemicals, 2008. http://www.cbirc.iastate.edu (accessed 01.25.15)

625 Chamberlin, A., 2014. Ethane production and its effects on natural gas processors.

626 http://marketrealist.com/2014/04/ethane-production-effects-natural-gas-processors/ (accessed $627 \quad 05.05 .15)$

628 Chemical Engineering Plant Cost Index (CEPCI), 2015.

629 http://www.chemengonline.com/economic-indicators/ (accessed 08.20.15)

630 Greenwood, A. I., 2013. US elevance starts supplying C18 diacid for new nylons, PU.

631 http:/www.icis.com/resources/news/2013/09/17/9706400/us-elevance-starts-supplying-c18-

632 diacid-for-new-nylons-pu/. (accessed 08.20.15)

633 ICIS Chemical Pricing, 2014. http://www.icis.com/about/price-reports/. (accessed 08.20.14)

634 United States Department of Agriculture, 2014. http://www.usda.gov/wps/portal/usda/usdahome

635 (accessed 08.05.14)

636 United States Energy Information Administration, 2014. http://www.eia.gov/ (accessed

$637 \quad 08.05 .14)$

638 United States Geological Survey, 2014. http://www.usgs.gov/(accessed 08.05.14)

639

640

641

642

643 


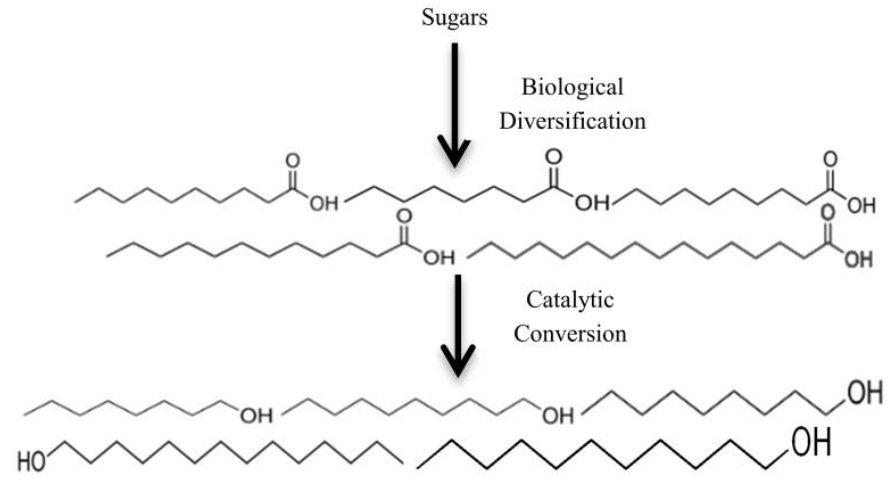

1-Octanol 1-Noanol 1-Decanol Undecanol 1-tetradecanol etc

651
Fig. 1- The carboxylic acid platform technology: Synthesis of wide array of fatty alcohols by coupling of biological and chemical catalysis (Single column)

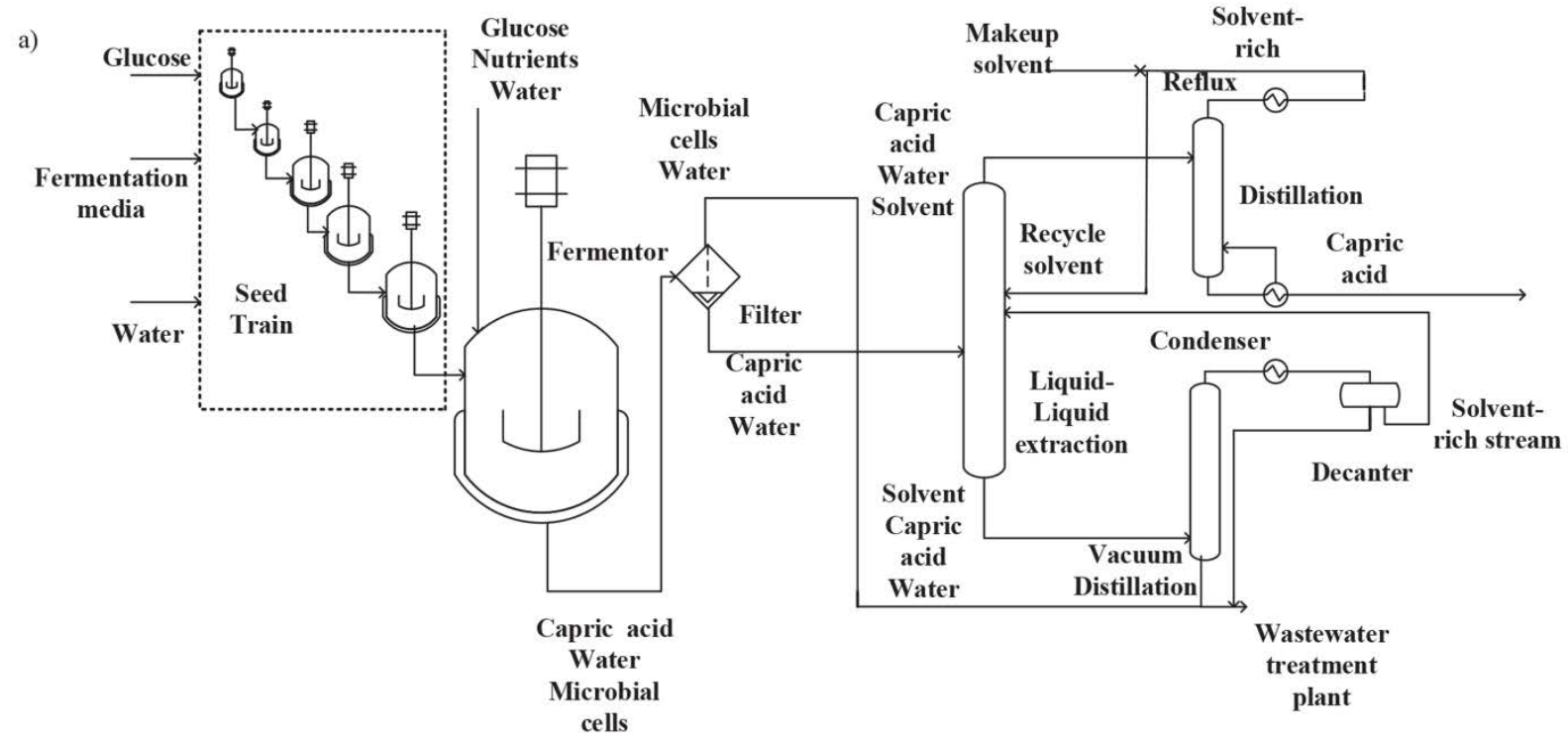


b)

Heat

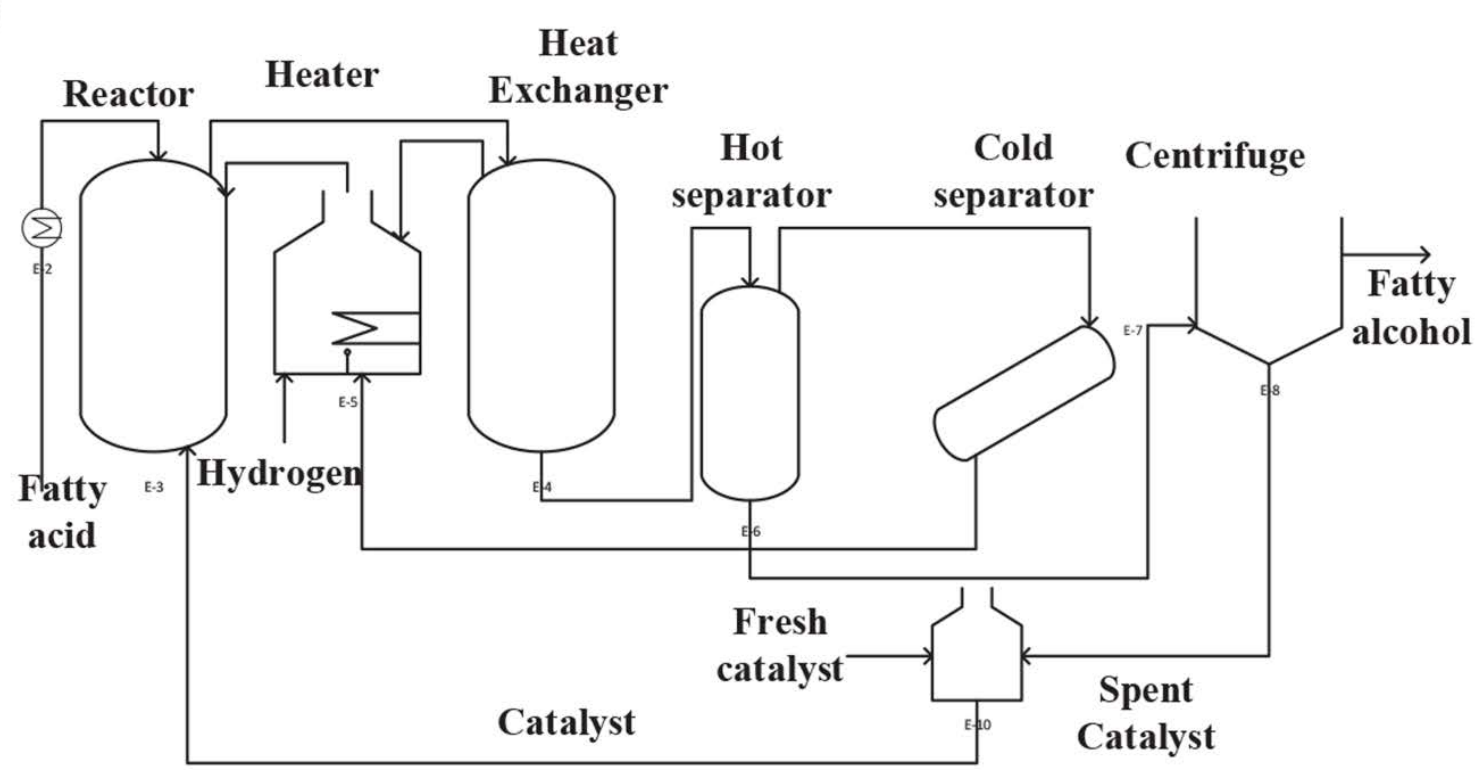

654

655

656

657

658

659

660

661

662

663

664

)

Fig. 2 (a) Fatty acid production process block diagram (adapted from Gunukula and Anex, unpublished work) (b) Fatty alcohol production process block diagram (adapted from Gervajio, 2012) (Double column)

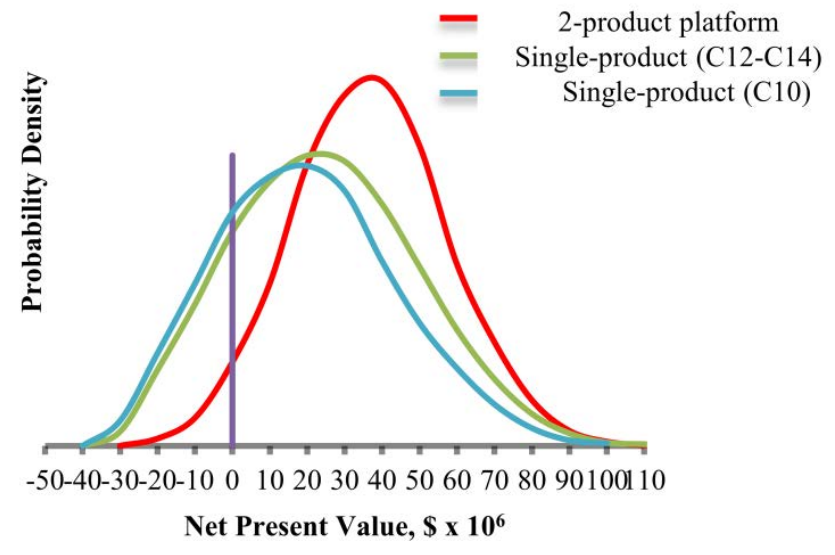

Fig.3 - NPV distributions for 2-product platform technology making 1-Decanol \& Blend of dodecanol and 1-tetradecanol and single product technology making either 1-Decanol or Blend of dodecanol and1-tetradecanol (Single column) 
665

666

667

668

669

670

671

672

673

674

675

676

677

678

679

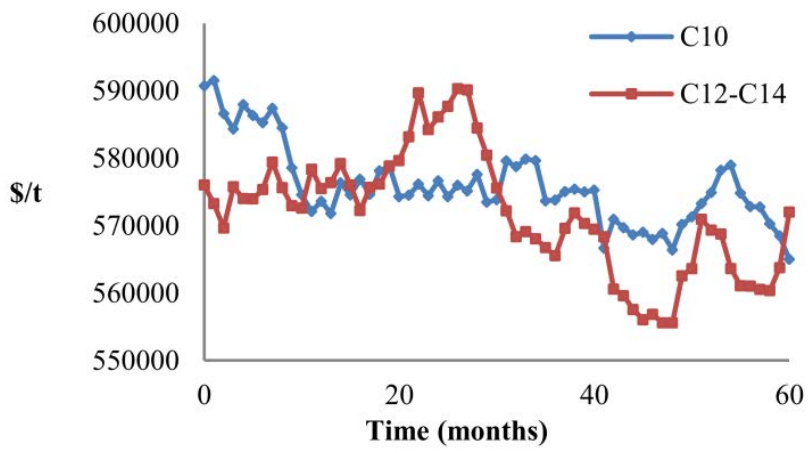

Fig. 4 - Five year forecast of net profits of 1-Decanol (C10) \& Blend of dodecanol and1tetradecanol (C12-C14) (Single column)

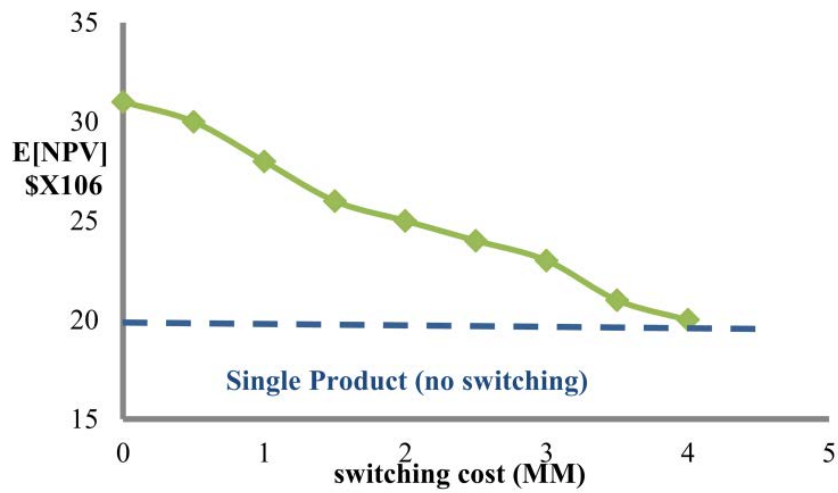

Fig. 5 - Effect of recurring switching cost on the expected NPV of 2-product platform technology making 1-Decanol \& Blend of dodecanol and1-tetradecanol (Single column) 
681 Table 1- Total capital cost estimation for fatty alcohol production Process

USD (in millions)

Total Equipment purchase cost (TEP)

9.2

Installed cost $(32 \%$ of TEP)

2.9

Instrumentation ( $43 \%$ of TEP)

3.9

Piping (31\% of TEP)

2.8

Electrical (10\% of TEP)

0.9

Buildings ( $15 \%$ of TEP)

1.38

Yard Improvements (12\% of TEP)

1.1

Service facilities (55\% of TEP)

5.0

Total Direct plant cost (TDC)

27.18

Engineering and supervision (32\% of TEP)

2.9

Construction Expenses (34\% of TEP)

3.1

Legal Expenses (4\% of TEP)

0.36

Contractor's fee (19\% of TEP)

1.17

Contingency (35\% of TEP)

3.2

Total indirect capital cost (TIC)

10.8

Working capital (10\% of TIC) $\quad 1.08$

$\begin{array}{ll}\text { Solvent cost } & 0.04\end{array}$

Catalyst cost $\quad 0.2$

Total capital cost

39.7

Table 2- Mean reverting parameters of economic variables

\begin{tabular}{llll}
\hline $\begin{array}{l}\text { Economic } \\
\text { Variable }\end{array}$ & $\begin{array}{l}\text { Long-run } \\
\text { mean }\end{array}$ & $\begin{array}{l}\text { Variance } \\
\text { parameter }\end{array}$ & $\begin{array}{l}\text { Reversion } \\
\text { Speed }\left(\text { day }^{-1}\right)\end{array}$ \\
\hline & & & \\
Glucose & $0.30(\$ / \mathrm{kg})$ & 0.004 & 0.15 \\
Natural gas & $3.35(\$ / \mathrm{MMBtu})$ & 0.014 & 0.018 \\
Electricity & $0.07(\$ / \mathrm{kWh})$ & 0.001 & 0.18 \\
Hydrogen & $2.5(\$ / \mathrm{kg})$ & 0.014 & 0.01 \\
Copper chromite & $8.5(\$ / \mathrm{kg})$ & 0.023 & 0.18 \\
1-Octanol & $2.2(\$ / \mathrm{kg})$ & 68.25 & 0.15 \\
1-Decanol & $2.0(\$ / \mathrm{kg})$ & 9.14 & 0.0033 \\
Blend of dodecanol and 1-tetradecanol & $1.9(\$ / \mathrm{kg})$ & 12.21 & 0.0017 \\
1-Hexadecanol & $1.6(\$ / \mathrm{kg})$ & 7.83 & 0.015 \\
\hline
\end{tabular}


687 Table 3- Results for impact of increase in number of products in the product suit Product suit of Technology $\quad$ Profitability Risk

Single-product technology

1-Octanol

\$29 MM

\$31 MM

1-Decanol

$\$ 20 \mathrm{MM}$

$\$ 26 \mathrm{MM}$

Blend of dodecanol and 1-tetradecanol

$\$ 12 \mathrm{MM}$

$\$ 25 \mathrm{MM}$

1-Hexadecanol

$-\$ 01 \mathrm{MM}$

$\$ 12 \mathrm{MM}$

Two-product technology

1-Octanol \& 1-decanol

$\$ 38 \mathrm{MM}$

$\$ 22 \mathrm{MM}$

1-Octanol \& Blend of dodecanol and1-tetradecanol

$\$ 37 \mathrm{MM}$

$\$ 21 \mathrm{MM}$

1-Octanol \& 1-hexadecanol

\$29 MM

$\$ 31 \mathrm{MM}$

1-Decanol \& Blend of dodecanol and1-tetradecanol

$\$ 31 \mathrm{MM}$

$\$ 20 \mathrm{MM}$

1-Decanol \& 1-hexadecanol

$\$ 20 \mathrm{MM}$

$\$ 26 \mathrm{MM}$

Blend of dodecanol and 1-tetradecanol \&1-Hexadecanol

$\$ 12 \mathrm{MM}$

$\$ 25 \mathrm{MM}$

Three-product technology

1-Octanol,1-decanol\& Blend of dodecanol and1-tetradecanol \$45 MM

$\$ 16 \mathrm{MM}$

688

689 